\title{
INFLUENCE OF CUO NANOPARTICLES IN ENHANCING THE OVERALL HEAT TRANSFER AROUND A SQUARE CYLINDER
}

\author{
Rafik Bouakkaz ${ }^{1 *}$ Yacine Khelili $^{1}$, Aliouali Abdelouahed ${ }^{2}$ \\ ${ }^{1}$ Military academy of Cherchell, Tipaza, Algeria \\ ${ }^{2}$ Département de Génie Mécanique, Université Mohamed khider Biskra, Algerie
}

Received 01.08.2019

Accepted 02.10.2019

\begin{abstract}
Steady flow and heat transfer through a copper-water nanofluid around a square cylinder was investigated numerically by using a finite-volume method for Reynolds numbers of 10-40. Furthermore, the range of nanoparticle volume fractions $(\phi)$ considered is $0 \leq \phi \leq 0.04$, with three different nanoparticle diameters dnp $=30,60$ and $90 \mathrm{~nm}$. The variation of the local and the average Nusselt numbers with Reynolds number, and volume fractions are presented for the range of the above conditions. The averaged Nusselt number showed clear enhancement comparing with the base fluids. This enhancement is more apparent in flows with higher particle volume concentration, whereas the particle diameter imposes an opposing effect on the heat transfer characteristics.
\end{abstract}

Keywords: nanofluid; heat transfer; square cylinder; steady regime.

\section{Introduction}

Nanofluid is a novel working fluid prepared by dispersing nanometer-sized solid particles such as $\mathrm{CuO}, \mathrm{Al}_{2} \mathrm{O} 3$, and $\mathrm{TiO}_{2}$ in traditional heat transfer fluid such as water, various oils (engine oil, pump oil) or ethylene glycol to increase thermal conductivity [12]. The addition of these particles of higher thermal conductivity to the fluid mentioned above enhances the thermal conductivity and thus increasing the heat transfer coefficient. Farooji et al. [3] have studied the momentum and forced convection heat transfer for a laminar and steady free stream flow of nanofluids past an isolated square. Various nanofluids consisting of $\mathrm{Al}_{2} \mathrm{O}_{3}$ and $\mathrm{CuO}$ with base fluids of water and a 60:40 (by mass) ethylene glycol and water mixture were selected to estimate their superiority over conventional fluids. They established that for any given particle diameter, there is an optimum value of particle concentration that results in the highest heat transfer coefficient. The fluid flow and heat transfer around a square cylinder utilizing $\mathrm{Al}_{2} \mathrm{O}_{3}-$

*Corresponding author: Rafik Bouakkaz,r.bouakkaz@gmail.com 
$\mathrm{H}_{2} \mathrm{O}$ nanofluid over low Reynolds numbers varied within the range of 1 to 40 and the volume fraction of nanoparticles $(\phi)$ is varied within the range of $0<\phi<0.05$ was also investigated by authors [4]. They found that the increasing the nanoparticles volume fractions augments the drag coefficient. Moreover, the pressure coefficient increases by increasing the solid volume fraction for sides where the pressure gradient is inverse but for sides where the pressure gradient is favourable, the pressure coefficient decreases. Recently, Rajpoot Rajendra and Dhinakaran [5] have carried out a meticulous study on the forced convective heat transfer from an unconfined heated square cylinder utilizing nanofluids with a multiphase modelling approach for different Reynolds number (10-40) and volume fractions of $\mathrm{Al}_{2} \mathrm{O}_{3}$ particles $(0-5 \%)$ in water. The results indicated that the effect of nanolayer thickness and nanoparticle diameter on the overall heat transfer rate can be studied. So, the aim of the present investigation had been motivated by increased interest and research in potential improvements in heat transfer characteristics using nanofluids. Effort has been made to investigate numerically the laminar flow of nanofluid and heat transfer characteristics for a range of Reynolds numbers $(10 \leq \mathrm{Re} \leq 40)$ and particle volumetric concentrations ranging from $0 \%$ to $4 \%$ with nanoparticle diameters of 30,60 and $90 \mathrm{~nm}$.

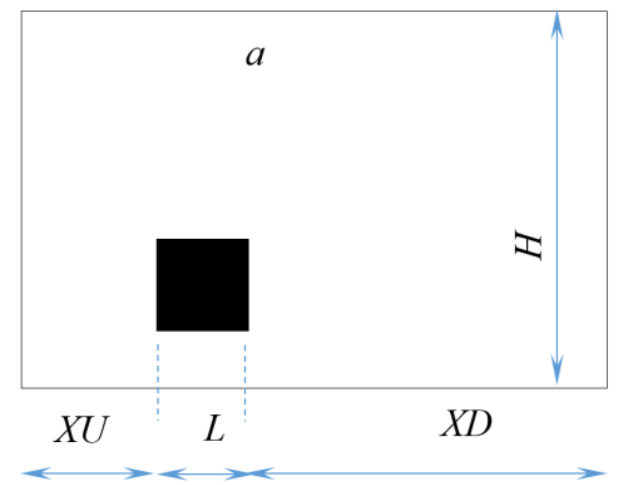

(a)

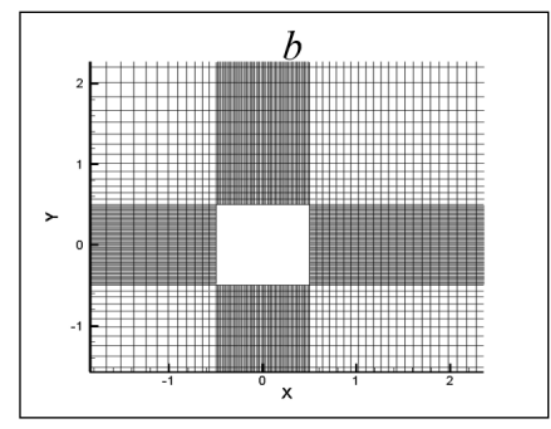

(b)

Fig. 1. a) Schematics computational domain, b) The grid system near the wall.

\section{The problem statement, governing equations, and boundary conditions}

The system of interest in this study is the unconfined flow around a twodimensional square cylinder with side $L$ (Figure 1 ). In this system, the square cylinder is placed symmetrically between the upper and lower boundaries and is maintained at a constant temperature $T_{w}$.

\section{Governing equations and boundary conditions}

The mixture model has a behavior similar to the single-phase model. Therefore, a single-phase approach is adapted for nanofluid modeling, in which the dissipation and operating pressure are neglected [16]. To use a single-phase approach, ultrafine ( $\leq 100$ $\mathrm{nm}$ ) solid particles are considered. The governing partial differential equations here are the Navier-Stokes and energy equations in two dimensions nanofluid flow around a square cylinder are given below: 


$$
\begin{aligned}
& \nabla\left(\rho_{n f} V_{m}\right)=0 \\
& \nabla\left(\rho_{n f} V_{m} V_{m}\right)=-\nabla(P)+\nabla\left(\mu_{n f} \nabla V_{m}\right) \\
& \nabla\left(\rho_{n f} C_{n f} V_{m} T\right)=\nabla\left(k_{n f} \nabla T\right)
\end{aligned}
$$

Where $\mathrm{V}_{\mathrm{m}}, P$ and $\mathrm{T}$ are velocity, pressure, and temperature, respectively.

The properties of nanofluids such as density, specific heat, thermal conductivity, and viscosity are calculated based on relations presented in the literature. These formulas are listed below:

$$
\begin{gathered}
\rho_{n f}=(1-\phi) \rho_{f}+\phi \rho_{n p} \\
(\rho C)_{n f}=(1-\phi)(\rho C)_{f}+\phi\left(\rho C_{p}\right)_{n p} \\
\mu_{n f}=\mu_{f}+\frac{\rho_{n p} V_{\beta} d_{n p}}{72 C \delta} \\
\text { in which: } \mathrm{V}_{\beta}=\frac{1}{\mathrm{~d}_{\mathrm{np}}} \sqrt{\frac{18 \mathrm{kT}}{\pi \rho_{\mathrm{np}} \mathrm{d}_{\mathrm{np}}}} ; \\
\mathrm{C}=\mu_{\mathrm{f}}^{-1}\left[\left(\mathrm{C}_{1} \mathrm{~d}_{\mathrm{np}} \times 10^{9}+\mathrm{C}_{2}\right) \phi+\left(\mathrm{C}_{3} \mathrm{~d}_{\mathrm{np}} \times 10^{9}+\mathrm{C}_{4}\right)\right]
\end{gathered}
$$

Where: $\mathrm{C}_{1}=-0.000001133 ; \mathrm{C}_{2}=-0.000002771 ; \mathrm{C}_{3}=0.00000009$; $\mathrm{C}_{4}=-0.000000393 ; \delta=\sqrt[3]{\frac{\pi}{6 \phi}} \mathrm{d}_{\mathrm{np}}$

$$
k_{n f}=k_{b f}\left[\frac{\left(k_{n p}+2 k_{f}\right)-2 \phi\left(k_{f}-k_{n p}\right)}{\left(k_{n p}+2 k_{f}\right)+\phi\left(k_{f}-k_{n p}\right)}\right]+5 X 10^{4} \times \beta \phi\left(\rho C_{p}\right)_{n f} \times \sqrt{\frac{\kappa T}{\rho_{s} d_{n p}}} f(\phi, T)
$$

$$
\begin{gathered}
f(\phi, T)=\left(2.8217 \times 10^{-2} \phi+3.917 \times 10^{-3}\right)\left(\frac{T}{T_{0}}\right)+-3.0669 \times 10^{-2} \phi+3.91123 \times 10^{-3} \\
\beta=8.4407 \times(100 \phi)^{-1.07304}
\end{gathered}
$$

Where $\phi$ is the solid volume fraction; the subscript nf stands for nanofluid; the subscript $f$ stands for base fluid and the subscript $n p$ stands for solid nanoparticles. The above expressions are valid for $298 \mathrm{~K} \leq \mathrm{T} \leq 363 \mathrm{~K}$. $\mathrm{T}_{0}$ is set at $273 \mathrm{~K}$. The copper nanoparticle properties are kept to be constant in the present study operating a range of 300, Table 1 . 
Table 1. Thermo-physical properties of the Copper nanoparticles.

\begin{tabular}{lc}
\hline Property & Copper \\
\hline$C_{p}\left(\mathrm{Kg}^{-1} \mathrm{~K}^{-1}\right)$ & 535.6 \\
$\rho\left(\mathrm{Kgm}^{-3}\right)$ & 6350 \\
$k\left(\mathrm{Wm}^{-1} \mathrm{~K}^{-1}\right)$ & 76.5 \\
\hline
\end{tabular}

The thermophysical properties of water taken from the literature [18] are:

$\rho_{f}=-0.0036 T^{2}+1.9159 T+748.19$

$C_{f}=-0.0001 T^{3}+0.1155 T^{2}-41.296 T+9017.8$

$\mu_{f}=0.00002414 \times 10^{\left(\frac{247.8}{T-140}\right)}$

$k_{f}=-8 X 10^{-6} T^{2}-0.0062 T-0.5388$

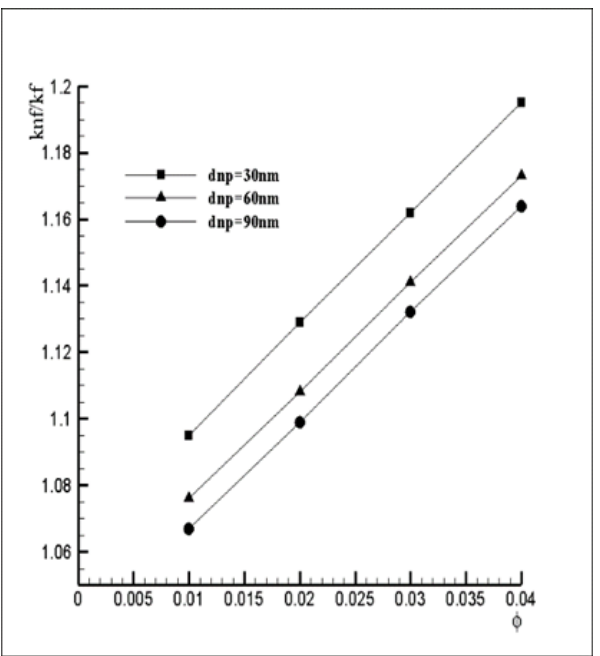

Fig. 2. Thermal conductivity ratio versus concentration $\emptyset$ of nanoparticles for different nanoparticle diameters $(T=300 \mathrm{~K})$.

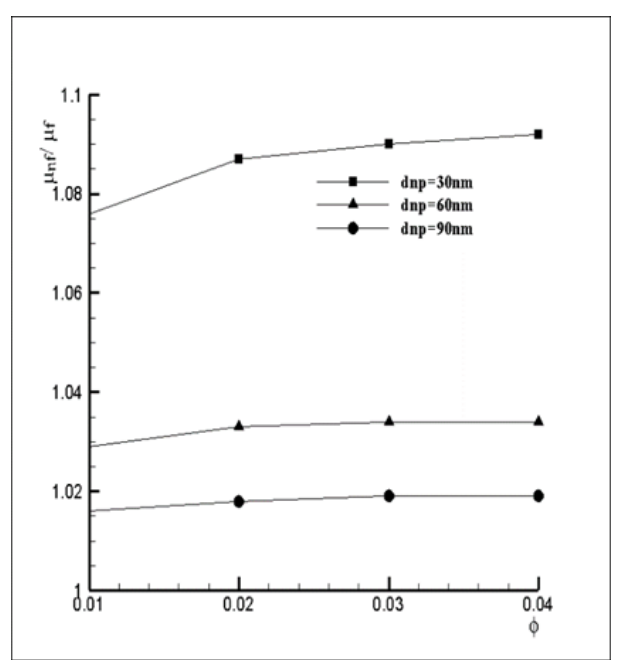

Fig. 3. Viscosity ratio versus concentration $\emptyset$ of nanoparticles for different nanoparticle diameters $(T=300 \mathrm{~K})$.

Figures 2 and 3 show the dimensionless effective thermal conductivity and viscosity based on Brownian motion. This model illustrates the trend of increasing thermal conductivity and viscosity with decreasing particle size. 
Boundary conditions

The dimensionless boundary conditions for the flow across a square cylinder surrounded by $\mathrm{Cu}$-water nanofluid can be written as:

The left-hand section, the Dirichlet-type boundary condition is defined as:

$$
V_{m, x}=V_{i n} ; V_{m, y}=0 ; T_{m}=T_{\text {in }}
$$

For the outlet boundary, the Neumann boundary condition was considered for both velocity and temperature fields. On the straight horizontal segments (slip boundary), a zero normal velocity and a zero normal gradient of all variables are prescribed:

$$
\partial V_{m, x} / \partial y=V_{m, y}=\partial T_{m} / \partial y=0
$$

Finally, the dimensionless peripheral or tangential velocity is prescribed on the surface of the cylinder along with a no-slip boundary condition

$$
V_{m, x}=V_{m, y}=0 ; T_{m}=T_{w}
$$

\section{Numerical details}

The steady, laminar, segregated solver was employed here to solve the incompressible flow on the collocated grid arrangement. Semi implicit method for the pressure linked equations (SIMPLE) was used to solve Navier-Stokes and energy equations for the above noted boundary conditions. Second-order upwind scheme is used to discretize the convective terms of momentum equations, whereas the diffusive terms are discretized by the central difference method. A convergence criterion of $10^{-8}$ is used for continuity, and $\mathrm{x}-\mathrm{y}$ components of momentum equations. While for energy equation, the criteria of convergence was $10^{-10}$.

\section{Domain independence study}

Four grids given in Table 2 are used in the grid-resolution study. Following earlier research $[3,17]$, the computational domain $X U / L=8$ and $X L / L=15$ was found to be an appropriate value. The grid resolution for $\operatorname{Re}=40$ at $\emptyset=0.04$ and $\mathrm{dnp}=60 \mathrm{~nm}$ was chosen. The results of grids 1 and 2 demonstrate considerable differences while the relative changes in the value of $\mathrm{cd}$ and $\mathrm{Nu}$ for grid 3 relative to grid 4 are only $0.29 \%$ and $0.72 \%$, respectively. Therefore, it was decided to carry out the computations in this work with grid G3.

Table 2. Details of the grids used at Re $=40$ for grid independence study.

\begin{tabular}{lcccc}
\hline Grids & grid size & XU & XL & H \\
\hline G1 & $80 \times 60$ & 8 & 15 & 20 \\
G2 & $163 \times 96$ & 8 & 15 & 20 \\
G3 & $274 \times 129$ & 8 & 15 & 20 \\
G4 & $342 \times 210$ & 8 & 15 & 20 \\
\hline
\end{tabular}




\section{Results and discussion}

Comparison with other results

The first step was to validate the problem set-up, the choice of numerical methods and mesh attributes by comparing results from our numerical simulations with results obtained from the literature. The outcomes included in the comparison were the mean Nusselt number.

Table 3. Comparison of Nu number and Drag coefficient computed in the present study with literature data.

\begin{tabular}{llcccccc}
\hline & \multicolumn{2}{c}{$\operatorname{Re}=5$} & \multicolumn{2}{c}{$\operatorname{Re}=20$} & \multicolumn{2}{c}{$\operatorname{Re}=40$} \\
& $\mathrm{CD}$ & $\overline{N u}$ & $\mathrm{CD}$ & $\overline{N u}$ & $\mathrm{CD}$ & $\overline{N u}$ \\
\hline Present study & 4.92 & 1.20 & 2.40 & 2.06 & 1.79 & 2.71 \\
Etminan-Farooji [3] & 4.83 & 1.27 & 2.43 & 2.07 & 1.83 & 2.72 \\
Paliwali et al. [7] & - & 1.22 & - & 2.07 & 1.98 & 2.71 \\
Sharma and Eswaran [6] & 4.86 & 1.24 & 2.35 & 2.05 & 1.75 & 2.71 \\
\hline
\end{tabular}

\section{Drag coefficient}

The relevant parameter computed from the velocity and pressure fields is the drag coefficient, which represents dimensionless expressions of the forces that the fluid produces on the cylinder.

The effect of nanoparticle diameters on the drag coefficient is shown in Figures 4. The figure clearly shows that decreasing the diameters of nanoparticles leads to increases in effective viscosity of the fluid and this increases viscous drag around the cylinder surface, thickens the hydrodynamic boundary layer, and exerts more retarding force on the shear layers. So, the drag coefficient increases by increasing solid volume fraction.

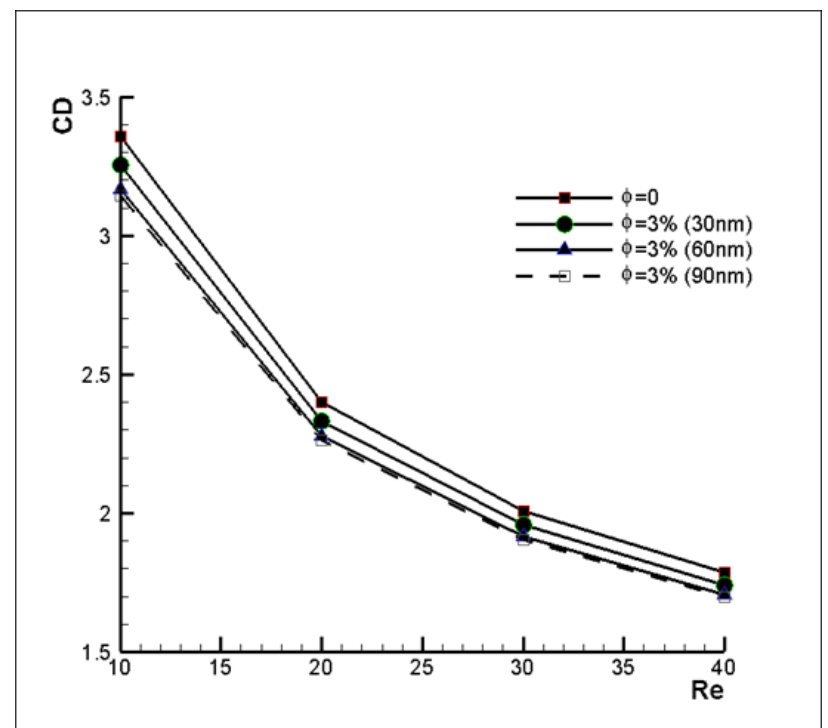

Fig. 4. Variation of drag coefficient (CD) on cylinder surface with Reynolds number for nanoparticle diameters various at $\emptyset=3 \%$. 


\section{Streamlines pattern}

The streamlines around the cylinder are compared between base fluid and nanofluid ( $\phi=0.04$ ) in figures 5 and 6 at Reynolds number of 20 and 40 at $\mathrm{np}=30 \mathrm{~nm}$. For high Reynolds number, the recirculation bubble becomes big and strong at the downstream side of the cylinder for both base fluid and nanofluid. However, in nanofluid, the center of bubbles is slightly pushed away from the surface of the cylinder comparing with base fluid. For the contours in Figure 7, it can be concluded that the increasing nanoparticles lead to reductions in effective viscosity and this increases Reynolds numbers. Hence, the bubble develops big at the downstream side of the cylinder. It is interesting to remind that the Reynolds and Prandtl number of nanofluids can be expressed as:

$$
R e_{n f}=\frac{\rho_{n f}}{\rho_{b f}} \frac{\mu_{b f}}{\mu_{n f}} R e_{b f} ; P r_{n f}=\frac{\mu_{n f}}{\mu_{b f}} \frac{C_{P, n f}}{C_{P, b f}} \frac{k_{b f}}{k_{n f}} P r_{b f}
$$
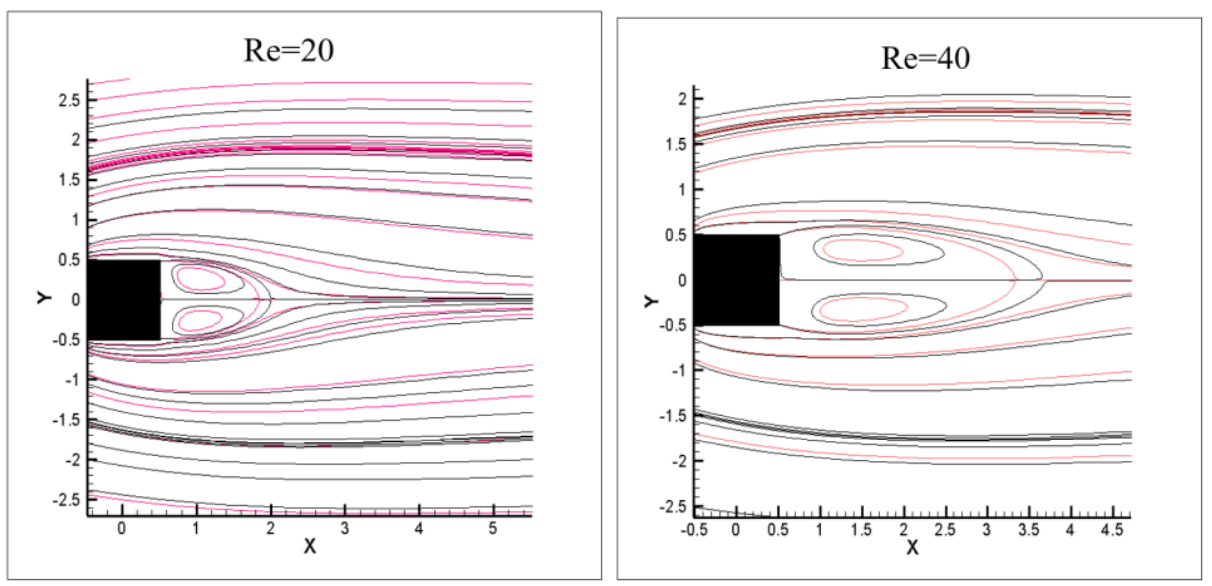

Fig. 5. Streamlines contours for the flow around the cylinder (red line refers to base fluid and black line refers to nanofluid); solid volume fraction 0.04 and nanoparticle diameter $n p=30 n m$ ). 


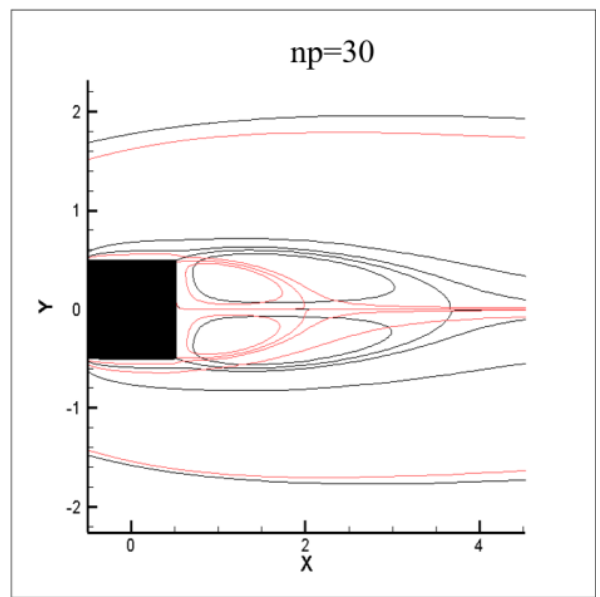

Fig. 6. Streamlines contours for the flow around the cylinder (red line refers to $R e=20$ and black line refers to $R e=40$ ( solid volume fraction 0.04 and nanoparticle diameter $\mathrm{np}=30 \mathrm{~nm}$ ).

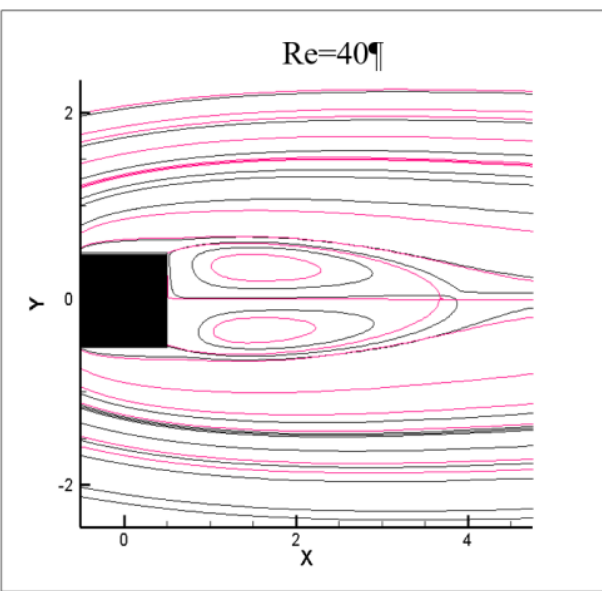

Fig. 7. Streamlines contours for the flow around the cylinder (red line refers to $n p=30$, and the black line refers to $n p=90$ ( solid volume fraction 0.04 and nanoparticle diameter $\mathrm{Re}=40$ ).

\section{Isotherm patterns}

The isotherms profiles around the cylinder for Reynolds number of 10 and 30 at $n p=60 \mathrm{~nm}$ are compared between base fluid and nanofluid $(\phi=0.04)$ in Figure 8 . Obviously, the temperature distribution contours for base fluid are overlaid with that for nanofluid. This can be explained as the addition of solid particles to the base fluid increases the Reynolds number of nanofluid. Hence, a higher capacity of transferring the heat from the cylinder. It is obvious from Figure 8 that the isotherms have a maximum density close to the front surface of the cylinder; this indicates high values of the local Nusselt number near the front stagnation point on the front surface as compared to other points on the cylinder surface.

\section{Local Nusselt number}

Figure 4 shows the variation of local Nusselt number $(\mathrm{Nu})$ on the surface of the cylinder with an increase in $\operatorname{Re}$ for various volume fractions $\varnothing$. When the solid concentration increases, the thermal conductivity improves and consequently, the local Nusselt number. Additionally, the thermal boundary layer is decreased by an increase in solid volume fraction. Therefore, the local Nusselt number is enhanced by any increase in solid volume fraction $(\varnothing)$. On the other hand, for all Re, the front surface has the highest Nusselt number, which is predictable according to isotherm patterns. 
R. Bouakkaz et al. - Influence of $\mathrm{CuO}$ nanoparticles in enhancing the overall heat transfer ... 233
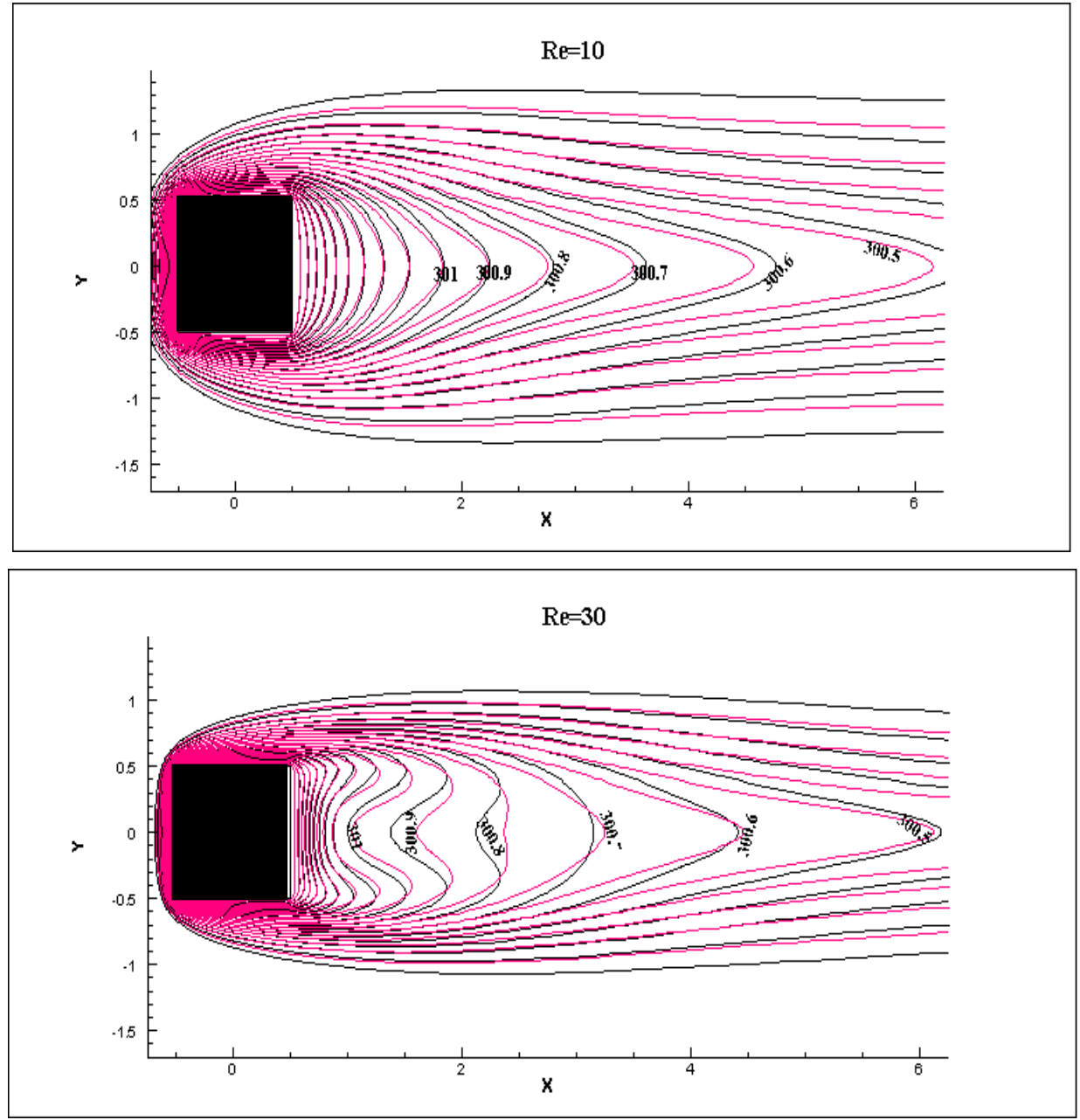

Fig. 8. The isotherm contours around the cylinder at different Reynolds number, (red line refers to water and black line refers nanofluid at solid volume fraction 0.04 and nanoparticle diameter $n p=60 \mathrm{~nm}$ ). 

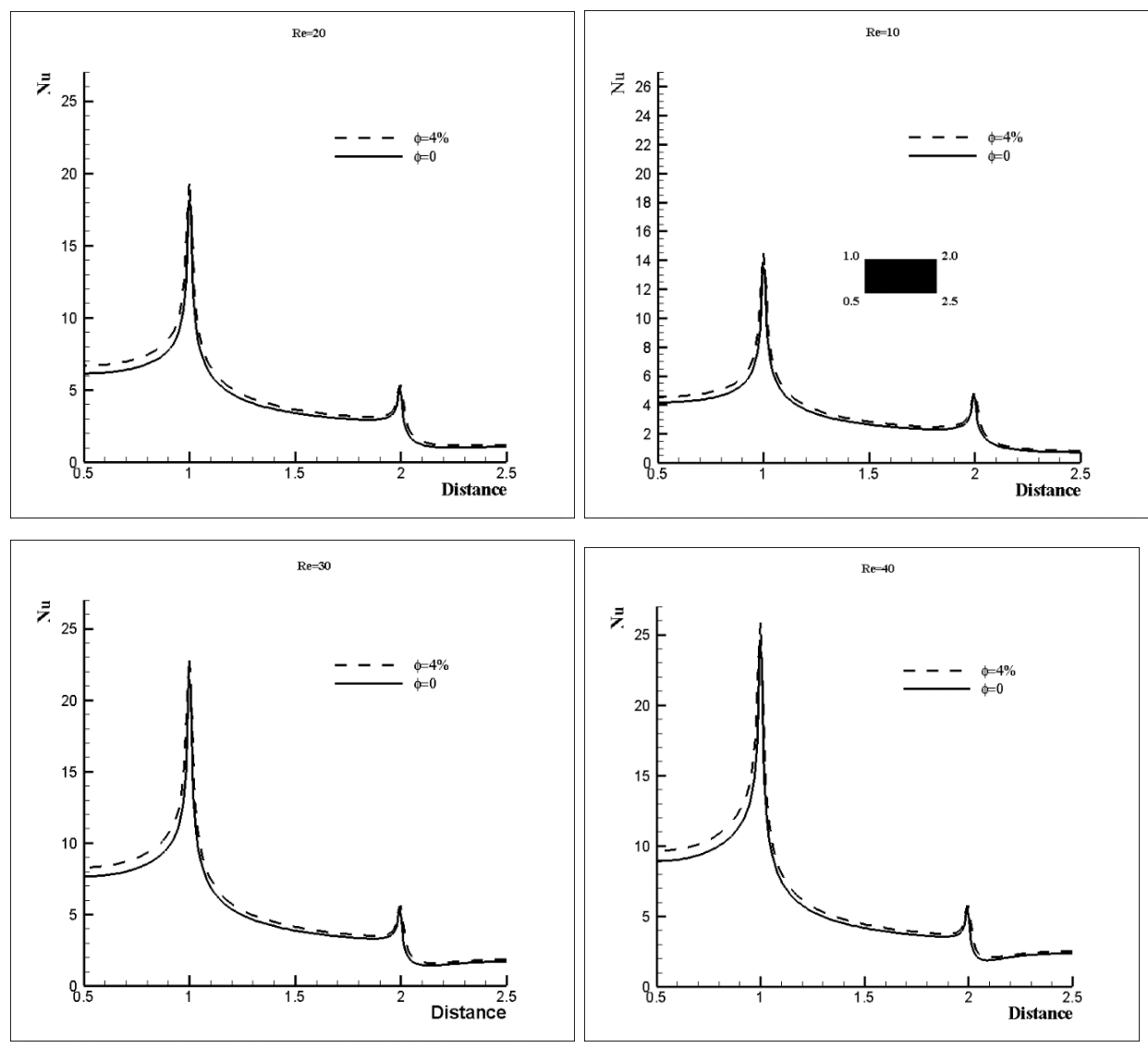

Fig. 9. Local Nusselt number along the cylinder surfaces for various Reynolds numbers at $\mathrm{np}=60 \mathrm{~nm}$.

\section{Averaged Nusselt number}

The effect of solid volume fraction on the averaged Nusselt number for different Reynolds numbers is shown in Figure 10. As expected, at any given solid volume fraction of nanoparticles $(\phi)$, the averaged Nusselt number increases with increasing Reynolds numbers. This can be explained as when Re number increases the inertia of flow increases, thus increasing the heat transfer. It can also be seen that the effect of particle concentration becomes further significant at higher Reynolds number. numbers. Further, Figure 11 presents the average Nusselt number at different nanoparticles diameters for various RE number at $\phi=0.03$. The results indicate that the average Nusselt number of nanofluid rises with increasing Reynolds number and decreases with an increase in particle diameter. 


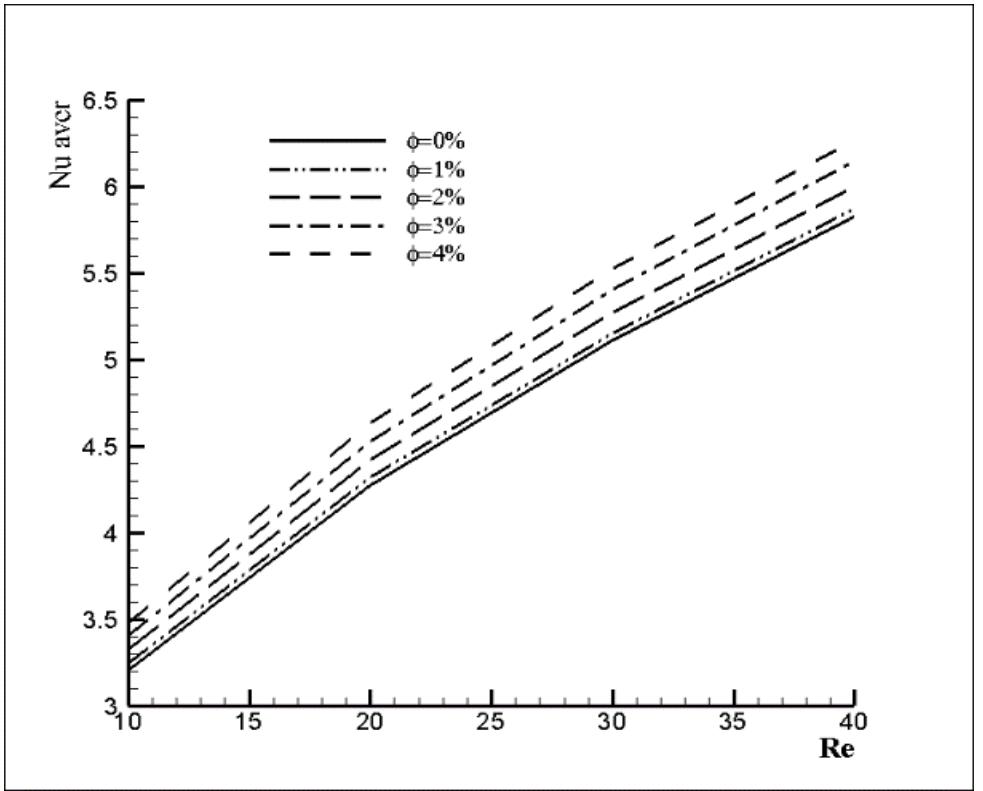

Fig. 10. Variation of average Nusselt number at various solid volume fractions for varying values of Reynolds number at $\mathrm{np}=60 \mathrm{~nm}$.

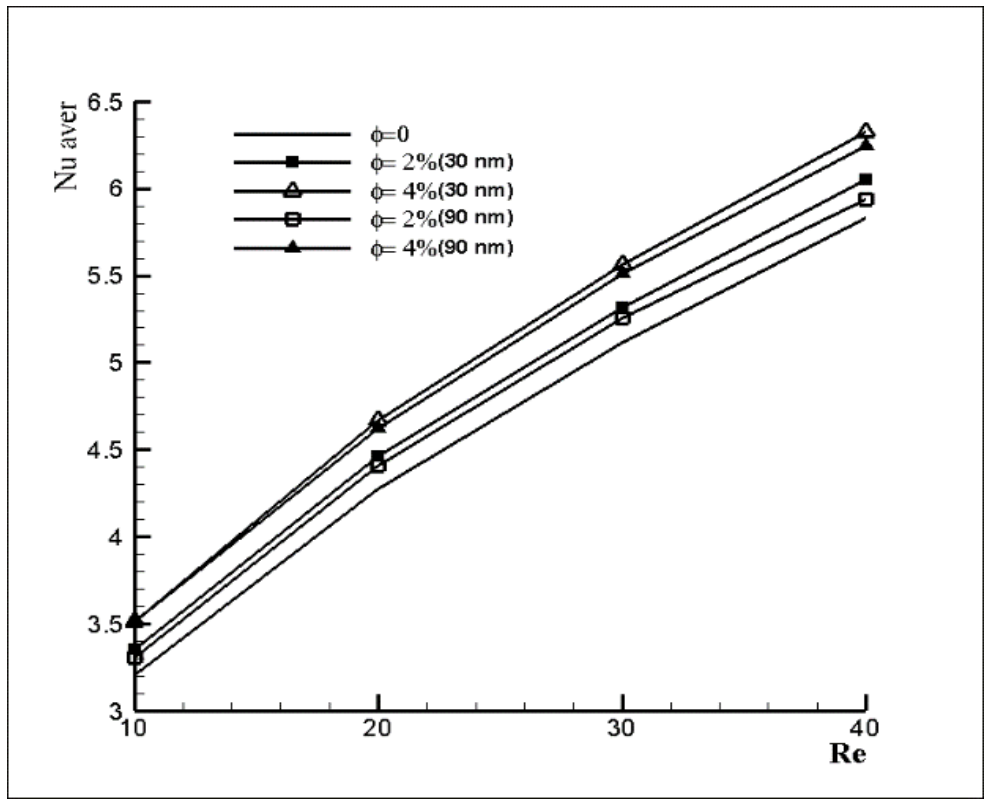

Fig. 11. Variation of average Nusselt number at various solid volume fractions and nanoparticle diameters for varying values of Reynolds number. 


\section{Conclusions}

The present study focuses on the unconfined laminar flow of nanofluid and heat transfer characteristics around a square cylinder in a steady regime. The illustrative streamline patterns and isotherm patterns are presented and examined for the above range of conditions. Further, it was showed that the decreasing diameter of nanoparticles lead to augments the drag coefficient. It was also concluded that heat transfer enhancement rises with the Reynolds number as well as particle concentration, but falls with increasing nanoparticle diameter $d n p$.

\section{References}

[1] R. Bouakkaz, F. Salhi, Y. Khelili, M. Quazzazi, K. Talbi: Archives of Thermodynamics, 38 (2017) 3-20.

[2] H. C. Brinkman: The Journal of Chemical Physics, 20 (1952) 571-571.

[3] V. Etminan-Farooji, E. E. Bajestan, H. Niazmand, S. Wongwises: Int J Heat Mass Transfer, 55 (2012) 1475-1485.

[4] M. S. Valipour, R. Masoodi, S. Rashidi, M. Bovand, M. Mirhosseini: Therm Sci, 18 (2014) 1305-1314.

[5] S. Rajpoot Rajendra, S. Dhinakaran: Proceedings, 4 (2017) 10069-10073.

[6] A. Sharma, V. Eswaran: Numer Heat Transfer A, 47 (1) (2004) 79-107.

[7] B. Paliwal, A. Sharma, R. P. Chhabra, V. Eswaran: Chem Eng Sci, 58 (23-24) (2003) 5315-5329.

[8] ASHRAE Handbook: Fundamentals, American Society of Heating, Refrigerating and Air-Conditioning Engineers Inc., Atlanta, GA, 2005.

[9] M. Izadi, A. Behzadmehr, D. Jalali-Vahida: Int J Therm Sci, 48 (2009): 2119-2129.

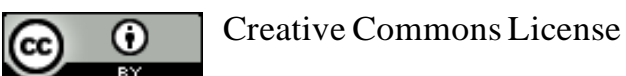

This work is licensed under a Creative Commons Attribution 4.0 International License. 